\title{
COMPARAÇÃO ENTRE TÉCNICAS DE EXTRAÇÃO DE HIDROCARBONETOS POLICÍCLICOS AROMÁTICOS EM TECIDOS HEPÁTICO E ADIPOSO DE TETRÁPODES MARINHOS E AVALIAÇÃO DA HETEROGENEIDADE DOS TECIDOS
}

\author{
Rafael André Lourenço*,a, Satie Taniguchia ${ }^{\text {a }}$, Josilene da Silva ${ }^{a}$, Patrick Simões Dias ${ }^{\text {e }}$ Márcia Caruso Bícego ${ }^{a}$ \\ Instituto Oceanográfico, Universidade de São Paulo, Praça do Oceanográfico, 191, 05508-120 São Paulo - SP, Brasil
}

Recebido em 01/09/2018; aceito em 28/11/2018; publicado na web em 24/01/2019

\begin{abstract}
COMPARISON BETWEEN SOXHLET AND MICROWAVE EXTRACTION TECHNIQUES FOR POLYCYLIC AROMATIC HYDROCARBONS IN LIVER AND ADIPOSE TISSUES OF MARINE TETRAPODS AND EVALUATION OF THE HETEROGENEITY OF TISSUES. For the evaluation of PAH extraction techniques in adipose and liver tissues of marine tetrapod, samples of some species (Pontoporia blainvillei, Chelonia mydas, Thalassarche melanophris, and Balaenoptera brydei) were spiked with PAH standards and extracted using soxhlet system and microwave oven. The results of both extraction techniques for the two different tissues of the four species of tetrapod were within the quality assurance and quality control criteria, that means both extraction techniques produced acceptable recoveries for surrogate and spiked compounds added to the sample tissues. Although both techniques of extraction met quality criteria and were considered suitable for extraction of marine tetrapod tissues, the soxhlet system produced a higher recovery of the spiked compounds and a lower standard deviation between the replicates than the microwave extraction; therefore the soxhlet system was considered the more efficient extraction method for PAH. The evaluation of liver and adipose tissue PAH accumulation, as well as the influence of tissue heterogeneity, was impaired as the concentrations of PAHs in almost all samples were lower than the detection limits of the analytical method.
\end{abstract}

Keywords: marine tetrapods; bioaccumulation of PAH; extraction techniques; soxhlet; microwave.

\section{INTRODUÇÃO}

Os hidrocarbonetos policíclicos aromáticos (HPA) são compostos ubíquos no ambiente marinho e têm como principais fontes os processos de combustão incompleta de combustíveis fósseis e de biomassa, além de vazamentos, exsudações naturais de petróleo e esgoto doméstico e industrial..$^{1-3}$ Devido à baixa solubilidade em água os HPA tendem a se associar com partículas orgânicas e inorgânicas em suspensão e então são depositados no sedimento marinho. ${ }^{4}$ A absorção dos HPA pelos animais marinhos pode ocorrer pelo contato da fase dissolvida e da fase particulada com as superfícies branquiais ou através da sua dieta. ${ }^{5-7}$ Organismos filtradores como moluscos bivalves podem acumular altas concentrações de HPA quando expostos a descargas constantes de esgoto ou vazamentos de petróleo. ${ }^{6}$ Já a acumulação em peixes se dá através do contato com as brânquias e pela dieta, enquanto que em vertebrados marinhos a exposição e absorção de HPA ocorre principalmente através da sua dieta. ${ }^{6}$ A posição dos organismos marinhos na teia trófica tem relação não apenas com a forma de absorção dos HPA como também com a sua capacidade de metabolização e de excreção desses compostos. De forma contrária ao que ocorre com os poluentes orgânicos persistentes (POP) como os pesticidas clorados e as bifenilas policloradas (PCB) que são biomagnificados ao longo da cadeia trófica, os HPA passam por um processo de diluição em direção aos organismos topo de cadeia. Essa diluição é resultado da combinação da baixa capacidade de assimilação de HPA e alta capacidade de metabolização desses compostos por organismos em posição superior na teia trófica. ${ }^{8-11}$

Em função das diferenças na forma de absorção, na capacidade de metabolização dos HPA pelos organismos e na lipofilicidade desses compostos, o acúmulo dos HPA pode ocorrer em maior ou menor grau em tecidos biológicos diferentes, como por exemplo no tecido

*e-mail: rafaell@usp.br adiposo, que funciona como reserva energética nos animais e no tecido hepático, que é onde ocorre a metabolização dos compostos.

Para avaliar e interpretar a bioacumulação de HPA por organismos marinhos é necessário realizar a análise desses compostos nos seus tecidos biológicos. Diversas técnicas são descritas na literatura para a extração de HPA de amostras sólidas como os tecidos biológicos. Dentre as mais comuns estão o sistema soxhlet, as micro-ondas, o ultrassom, a agitação mecânica e a extração acelerada com solvente ou fluido pressurizado (ASE), que são técnicas já estabelecidas e recomendadas por agências de controle ambiental. ${ }^{12-16} \mathrm{~A}$ escolha de uma outra técnica de extração envolve, entre diversos fatores, o tempo de extração, a quantidade de solvente orgânico necessário, a polaridade do solvente, a disponibilidade do equipamento, além da eficiência da extração para uma matriz específica e o custo da análise. O sistema soxhlet é o método de extração padrão e de referência para a análise de HPA em amostras sólidas, ${ }^{13}$ contudo trata-se um procedimento demorado ( $8 \mathrm{~h}$ de extração ou mais) e que requer grandes quantidades de solventes orgânicos ( $80 \mathrm{~mL}$ ou mais). ${ }^{17} \mathrm{~A}$ extração simultânea de diferentes amostras depende da disponibilidade de mantas de aquecimento, vidraria, espaço de bancada e exaustão adequada para os gases. A extração por micro-ondas ${ }^{14}$ é mais rápida (15 minutos de extração), requer uma quantidade menor de solventes orgânicos $(<50 \mathrm{~mL})^{17} \mathrm{e}$ é um método mais prático do que o soxhlet, visto que é realizada em único instrumento. Outro aspecto importante é a exposição do analista aos solventes, que é melhor controlada no caso da extração assistida por micro-ondas. A desvantagem é o tempo necessário para o resfriamento do sistema, que pode levar algumas horas, além do custo do equipamento, que é maior do que o Soxhlet. O número de extrações simultâneas possível no sistema de micro-ondas é limitada pelo suporte de frascos do próprio equipamento de micro-ondas. A técnica de extração acelerada por solvente ${ }^{15}$ requer um volume baixo de solvente orgânico (em geral $<20 \mathrm{~mL}$ ) e a extração ocorre em um tempo curto, menos de 20 minutos. ${ }^{17}$ Contudo o equipamento extrai uma amostra por vez, então dependendo do numero de amostras, 
o equipamento deixa de ser vantajoso em relação aos demais no quesito tempo.

Diversos trabalhos foram publicados recentemente no Brasil envolvendo a análise de compostos orgânicos (HPA e POP) em tecidos biológicos de tetrápodes marinhos utilizando como método de extração soxhlet ou micro-ondas, ${ }^{6,18-24}$ contudo nenhum desses trabalhos apresentou a comparação entre as diferentes técnicas de extração ou uma avaliação sobre a homogeneidade dos tecidos de tetrápodes marinhos. O propósito deste trabalho foi o de apresentar uma avaliação e a validação desses dois métodos de extração de HPA (soxhlet e micro-ondas) em diferentes tecidos biológicos (tecido adiposo e hepático) de tetrápodes marinhos juntamente com a avaliação das diferenças na acumulação de HPA em um ou outro tecido. Espera-se assim fornecer subsídios aos órgãos ambientais para a avaliação da bioacumulação de HPA em tecidos de tetrápodes marinhos.

\section{MATERIAIS E MÉTODOS}

\section{Escolha dos animais e dos tecidos}

Para a avaliação dos métodos de extração e avaliação dos tecidos biológicos foram utilizadas amostras de tecido adiposo da região ventral e tecido hepático de carcaças código 2 (carcaça em boa condição ou fresca), segundo a sistemática de classificação de carcaças proposta por Geraci e Lounsboury, ${ }^{25}$ dos seguintes tetrápodes marinhos: Pontoporia blainvillei (toninha), Chelonia mydas (tartaruga verde), Thalassarche melanophris (albatroz de sobrancelha) e Balaenoptera brydei (baleia de bryde).

Para a avaliação da heterogeneidade e do local de retirada do tecido foram utilizadas carcaças código 2 recém coletadas de P. blainvillei, C. mydas e Spheniscus magellanicus (pinguim de magalhães) conforme descrito a seguir. Da carcaça de P. blainvillei foram coletadas amostras de tecido adiposo em três partes diferentes do animal, sendo elas: junto à nadadeira caudal, à nadadeira dorsal e da região ventral. As amostras de tecido hepático também foram coletadas em três locais diferentes do fígado, denominadas cranial (mais próximo à cabeça), medial (parte central) e caudal (mais próxima à cauda). ${ }^{26}$ Da carcaça de C. mydas foram coletadas amostras de tecido hepático e adiposo de três partes diferentes do animal, denominadas cranial, medial e caudal. ${ }^{26}$ Da carcaça de $S$. magellanicus foram coletadas amostras de tecido hepático de três partes distintas, cranial, medial e caudal. ${ }^{26}$ A coleta de tecido adiposo foi possível apenas em um local (ventre) devido ao baixo teor de gordura do animal encontrado.

As diferenças de amostragem entre os animais tanto para a avaliação do método de extração quanto para a avaliação da heterogeneidade do tecido ocorreram devido à disponibilidade de tecidos. Os tecidos foram mantidos em temperatura $-80^{\circ} \mathrm{C}$ desde a coleta até o momento das análises, de acordo com as recomendações de Geracy e Lounsboury. ${ }^{25}$

\section{Materiais utilizados}

Todo material utilizado, vidraria, pinças, lâminas, tubos de micro-ondas, etc. foi imerso em solução com detergente alcalino Extran ${ }^{\circledR}$ durante 24 horas, enxaguado com água da torneira e com água deionizada, seco em estufa ou, no caso de materiais volumétricos, em temperatura ambiente. Após seco, todo o material foi descontaminado com diclorometano e n-hexano (Merck, Alemanha) de pureza grau pesticida antes da utilização. De forma alternativa, quando as características do material permitiram, o material foi calcinado a 400 ${ }^{\circ} \mathrm{C}$ durante 4 horas. Agentes secantes e adsorventes como sulfato de sódio (J.T. Baker, EUA), sílica e alumina (Merck, Alemanha) foram calcinados a $400{ }^{\circ} \mathrm{C}$ antes de serem utilizados. A água utilizada para desativar a sílica e a alumina foi deionizada e posteriormente extraída 5 vezes com $\mathrm{n}$-hexano $(30 \mathrm{~mL}$ de $\mathrm{n}$-hexano para cada $2 \mathrm{~L}$ de água, a cada extração).

Para a construção da curva de calibração analítica e fortificação das amostras com os 16 HPA prioritários foi utilizado o padrão PAH-MIX (Z-014G), além de benzo[e]pireno, dibenzotiofeno e perileno (AccuStandard, EUA). Como padrão interno foi utilizada a mistura de HPA deuterados contendo naftaleno- $\mathrm{d}_{8}$, acenafteno- $\mathrm{d}_{10}$, fenantreno- $\mathrm{d}_{10}$, criseno- $\mathrm{d}_{12}$ e perileno- $\mathrm{d}_{12}$ (Internal Standard Mix Z-014J, AccuStandard, EUA). ${ }^{27}$ Como padrão sub-rogado foi utilizado o p-terfenil-d ${ }_{14}$ (M-8270-SS, AccuStandard, EUA). ${ }^{27}$

\section{Preparação das amostras de gordura e de fígado para a avaliação do método de extração e do tecido}

Para a análise de HPA, tanto em tecido adiposo quanto em tecido hepático, de cada um dos animais, C. mydas, P. blainvillei, T melanophris e B. brydei, foram feitas subamostragens da parte interna da amostra original de forma a evitar possíveis contaminações que possam ter ocorrido na superfície da amostra em qualquer uma das etapas de coleta, de manuseio ou de armazenamento das amostras. Destas subamostras, separou-se $0,25 \mathrm{~g}$ que foram pesados sobre papel alumínio utilizando balança analítica.

Essa fração de $0,25 \mathrm{~g}$ de amostra foi então macerada com $10 \mathrm{~g}$ de sulfato de sódio anidro em gral com pistilo para a retenção da água presente na amostra. Nos casos em que a gordura apresentou resistência à maceração, como no caso da gordura do $P$. blainvillei, foi necessário triturar a gordura utilizando pinça e lâmina de forma a possibilitar o melhor contato entre a amostra e o sulfato de sódio.

Essas amostras maceradas foram transferidas para cartuchos de vidro com fundo poroso de vidro sinterizado para a extração por soxhlet e para frascos de teflon GreenChem ${ }^{\circledR}$ para a extração por micro-ondas. As amostras foram então fortificadas com os 16 HPA prioritários além de benzo[e]pireno, dibenzotiofeno e perileno em dois níveis de concentração, baixo (concentração final de $20 \mathrm{ng} \mathrm{g}^{-1}$ peso úmido) e alto (concentração final de $2000 \mathrm{ng} \mathrm{g}^{-1}$ peso úmido). Houve a necessidade de fortificação das amostras pois análises preliminares indicaram concentrações não detectáveis nos tecidos, o que impossibilitaria a comparação das eficiências dos métodos de extração. Além da fortificação foi adicionado às amostras o padrão sub-rogado p-terfenil-d $\mathrm{d}_{14}(500 \mathrm{ng})$.

Esse procedimento foi repetido para a formação de cinco replicatas de amostras de tecido adiposo e para a formação de cinco replicatas de tecido hepático de cada um dos quatro animais, para cada um dos dois níveis de fortificação, para cada um dos dois tipos de extração, totalizando assim, vinte replicatas de cada tecido de cada um dos quatro animais, o que gerou um total de 160 amostras (Figura 1).

\section{Preparação das amostras de gordura e de fígado para a avaliação da heterogeneidade dos tecidos e do local de retirada do tecido adiposo}

Para avaliar a influência da heterogeneidade dos tecidos nas replicatas foram realizadas análises de HPA em quatro amostras: três amostras de cada tecido, adiposo e hepático, coletadas em três locais diferentes; e uma quarta amostra composta de cada tecido destes três locais (Figura 2). Essa avaliação foi realizada de forma completa para os tecidos de P. blainvillei e de C. mydas. Para o S. magellanicus, a avaliação foi realizada apenas em tecido hepático devido à ausência de tecido adiposo em massa suficiente.

As amostras compostas foram preparadas a partir de $0,25 \mathrm{~g}$ de cada amostra de tecido, que foram maceradas e homogeneizadas. Uma massa de $0,25 \mathrm{~g}$ dessa amostra composta foi separada para análise. 
Para avaliar a influência do local de coleta de tecido adiposo do corpo do animal foram realizadas análises de HPA em cinco replicatas de tecidos retirados de dois diferentes locais (Figura 2). Para a avaliação em $P$. blainvillei, optou-se pelos tecidos retirados junto à nadadeira dorsal e da região ventral. Em C. mydas optou-se pelo tecido adiposo retirado das regiões cranial e medial. ${ }^{26} \mathrm{Em} S$. magellanicus foram realizadas análises apenas de tecido da região ventral. A opção por tais locais se deu em função da massa de amostra disponível.

O experimento para a avaliação da heterogeneidade dos tecidos e da influência do local de retirada do tecido adiposo totalizou
45 amostras, que receberam o mesmo tratamento citado anteriormente, excluindo-se a fortificação com HPA.

\section{Extração das amostras por soxhlet}

A extração das amostras por soxhlet foi realizada seguindo os cuidados dispostos no protocolo da USEPA 3540c. ${ }^{13}$

Os cartuchos de vidro contendo as amostras já com padrão sub-rogado e/ou fortificadas foram inseridos nos extratores soxhlet (volume do extrator $=60 \mathrm{~mL}$ ) acoplados a balões de vidro de

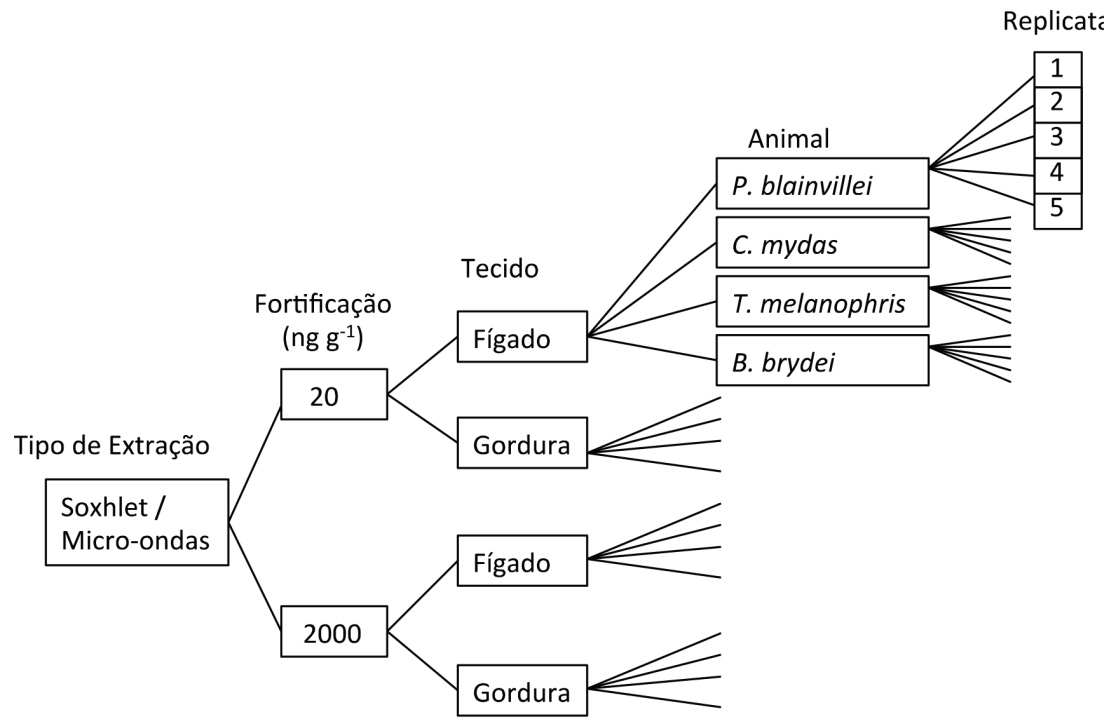

Figura 1. Esquematização do experimento para a avaliação do método de extração e do tecido do animal

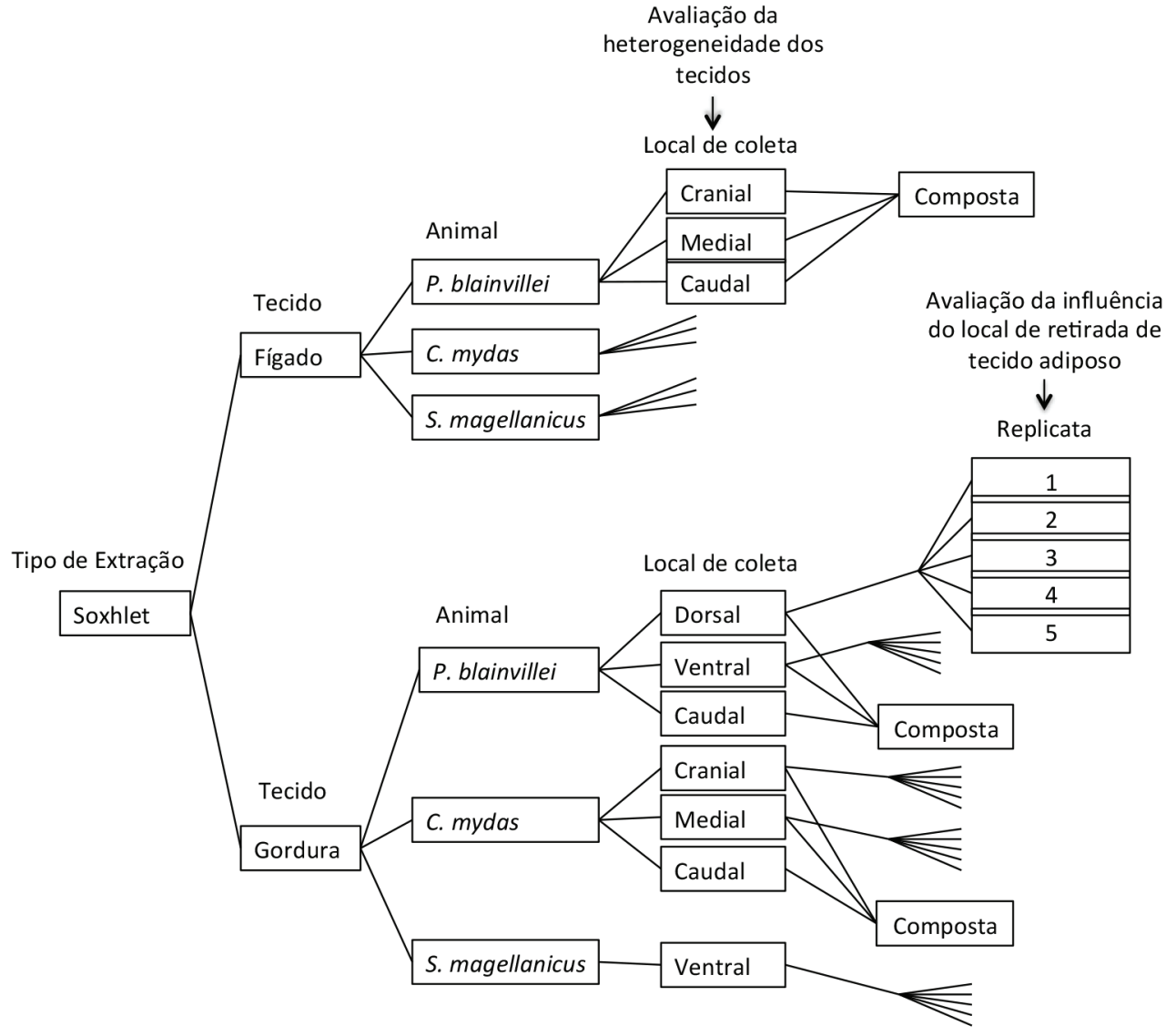

Figura 2. Esquematização do experimento para a avaliação da heterogeneidade dos tecidos e da influência do local de coleta do tecido adiposo 
$125 \mathrm{~mL}$ contendo $80 \mathrm{~mL}$ de mistura de n-hexano com diclorometano $(1: 1, v: v)$. Em cada batelada de extração foram extraídas simultaneamente 23 amostras, que é o número de sistemas soxhlet disponível no laboratório. A extração foi realizada durante o período de 8 horas.

Após a extração e resfriamento do sistema os extratos foram concentrados para $1 \mathrm{~mL}$ em evaporador rotativo com pressão reduzida, de onde se retirou $0,1 \mathrm{~mL}$ para determinação do teor lipídico.

\section{Extração das amostras por micro-ondas}

Para a extração por micro-ondas foi utilizado um aparelho de micro-ondas CEM modelo MARS-X 230/60 (CEM, EUA) equipado com frascos de teflon GreenChem ${ }^{\circledR}$ e agitação magnética individual nos frascos. O sistema permite o posicionamento simultâneo de até 14 frascos GreenChem ${ }^{\circledR}$. A extração das amostras por micro-ondas foi realizada seguindo os cuidados dispostos no protocolo da USEPA $3546 .{ }^{14} \mathrm{Em}$ cada batelada de extração foram extraídas simultaneamente 12 amostras, que é o número de frascos disponíveis no laboratório.

Os frascos de teflon contendo as amostras já com padrão sub-rogado e/ou fortificadas foram submetidos às condições de extração adaptadas de metodologias estabelecidas na literatura e otimizadas para análise de contaminantes orgânicos em tecidos biológicos. ${ }^{23,28,29}$ Para a extração foram utilizados $40 \mathrm{~mL}$ de mistura de n-hexano com diclorometano $(1: 1, \mathrm{v}: \mathrm{v})$. O forno de micro-ondas foi programado para aquecer a $115^{\circ} \mathrm{C}$ durante 15 minutos.

Após a extração e o resfriamento do sistema (cerca de 6 horas), os extratos foram concentrados para $1 \mathrm{~mL}$ em evaporador rotativo com pressão reduzida, de onde se retirou $0,1 \mathrm{~mL}$ para determinação do teor lipídico.

\section{Determinação do peso lipídico}

Para a determinação do peso lipídico foi seguido o método gravimétrico descrito no protocolo USEPA $1699 .{ }^{30}$ Os $0,1 \mathrm{~mL}$ dos extratos orgânicos foram transferidos para frascos de vidro previamente pesados em balança analítica. Após a evaporação total do solvente em temperatura ambiente cada frasco foi novamente pesado e a diferença de massa (resíduo) foi utilizada no cálculo da percentagem de lipídios.

\section{Purificação dos extratos}

Para a etapa de purificação dos extratos orgânicos contendo os HPA, tanto para as amostras de gordura quanto para as amostras de fígado, independentemente do tipo de extração, soxhlet ou micro-ondas, foi utilizado o mesmo procedimento, com adaptações da metodologia estabelecida na literatura. ${ }^{31,32}$ Foram seguidas também as recomendações e cuidados dispostos nos protocolos USEPA 3610, USEPA 3630 e USEPA $3640 . .^{33-35}$

Os $0,9 \mathrm{~mL}$ de cada um dos extratos restantes foram eluídos com $80 \mathrm{~mL}$ de mistura de n-hexano e diclorometano (1:1, v:v) através de coluna de vidro ( $25 \mathrm{~cm}$ de altura x $1,5 \mathrm{~cm}$ de diâmetro interno) contendo $8 \mathrm{~g}$ de sílica gel sobre $16 \mathrm{~g}$ de alumina e $1 \mathrm{~g}$ de sulfato de sódio no topo. A sílica e a alumina foram previamente desativadas em 5\% com água (água deionizada e extraída com n-hexano). Esse procedimento teve como finalidade reduzir parcialmente a carga de lipídios para a purificação complementar além da retirada de outros compostos relativamente mais polares que os HPA.

Para purificação complementar, o eluato da coluna de vidro foi concentrado a $0,5 \mathrm{~mL}$ em evaporador rotativo com pressão reduzida e injetado no cromatógrafo a líquido de alta eficiência (CLAE - Perkin
Elmer LC-250) acoplado a um detector de UV/Visível (Perkin Elmer, LC-95) equipado com uma pré-coluna (Phenomenex 286039-8, Phenogel 03B-2090K0 Guard $10 \mu \mathrm{L}, 50$ x 7,8 mm) seguida de duas colunas de exclusão por tamanho conectadas em série (Phenogel $10 \mu, 100$ A, 22,5 x 250 mm, Phenomenex, EUA). Diclorometano foi utilizado para a eluição com um fluxo de $5 \mathrm{~mL} \mathrm{~min}^{-1}$. Para o monitoramento da eluição dos HPA foi utilizado o detector UV/visível no comprimento de onda de $254 \mathrm{~nm}$. Os lipídios remanescentes da coluna de vidro foram eluídos entre 0 e 30 min e essa fração foi descartada. Na sequência foi coletada a fração contendo os HPA, eluída entre 30 e $40 \mathrm{~min}$.

Os extratos das amostras que receberam fortificação de $20 \mathrm{ng} \mathrm{g}^{-1}$ foram concentrados para $90 \mu \mathrm{L}$ em evaporador rotativo com pressão reduzida seguindo de fluxo de $\mathrm{N}_{2(\mathrm{~g}) \text {, }}$ onde adicionou-se $50 \mathrm{ng}$ de cada padrão interno deuterado (naftaleno- $\mathrm{d}_{8}$, acenafteno- $\mathrm{d}_{10}$, fenantreno- $\mathrm{d}_{10}$, criseno- $\mathrm{d}_{12}$ e perileno- $\left.\mathrm{d}_{12}\right)$.

Os extratos das amostras que receberam fortificação de $2000 \mathrm{ng} \mathrm{g}^{-1}$ e os extratos que não receberam fortificação foram concentrados para $900 \mu \mathrm{L}$ onde adicionou-se $500 \mathrm{ng}$ de cada padrão interno deuterado citado anteriormente.

\section{Identificação e quantificação dos HPA}

A análise e quantificação dos HPA foi realizada seguindo o disposto no protocolo USEPA $8270 .{ }^{27}$

Foi preparada a curva de calibração analítica para a quantificação dos HPA (16 HPA prioritários, benzo[e]pireno, dibenzotiofeno e perileno) abrangendo a faixa de concentração no extrato entre $0,05 \mathrm{ng} \mu \mathrm{L}^{-1}$ e $5,0 \mathrm{ng} \mu \mathrm{L}^{-1}$. De forma a melhorar a precisão e exatidão analítica, a curva de calibração foi dividida em duas partes, a primeira variando entre $0,05 \mathrm{ng} \mu \mathrm{L}^{-1}$ e $1,2 \mathrm{ng} \mu \mathrm{L}^{-1}\left(0,05 \mathrm{ng} \mu \mathrm{L}^{-1}, 0,1 \mathrm{ng} \mu \mathrm{L}^{-1}\right.$, $0,25 \mathrm{ng} \mu \mathrm{L}^{-1}, 0,5 \mathrm{ng} \mu \mathrm{L}^{-1}, 0,8 \mathrm{ng} \mu \mathrm{L}^{-1}$ e $\left.1,2 \mathrm{ng} \mu \mathrm{L}^{-1}\right)$ e a segunda variando entre $1,2 n g \mu \mathrm{L}^{-1}$ e $5,0 \mathrm{ng} \mu \mathrm{L}^{-1}\left(1,2 \mathrm{ng} \mu \mathrm{L}^{-1}, 2,0 \mathrm{ng} \mu \mathrm{L}^{-1}, 2,5 \mathrm{ng} \mu \mathrm{L}^{-1}\right.$, $\left.3,5 \mathrm{ng} \mu \mathrm{L}^{-1}, 5,0 \mathrm{ng} \mu \mathrm{L}^{-1}\right)$. A equação de reta da curva de calibração de cada um dos compostos apresentou coeficiente de determinação $\left(\mathrm{R}^{2}\right)$ superior a 0,99 .

Os HPA foram analisados no cromatógrafo a gás equipado com espectrômetro de massas (CG-EM) Agilent Technologies $6890 / 5973$ N. A aquisição dos dados foi feita em modo de monitoramento seletivo de íons

A temperatura no injetor e na interface foi programada em $280^{\circ} \mathrm{C}$ e a temperatura na fonte de íons foi programada em $300{ }^{\circ} \mathrm{C}$. Foi utilizada uma coluna cromatográfica HP-5MS (Agilent J\&W GC columns) com 30 metros de comprimento, 0,25 mm de diâmetro interno e $0,25 \mu \mathrm{m}$ de espessura de filme de $5 \%$ fenilmetilsiloxana. A rampa de temperatura do cromatógrafo teve início em $40^{\circ} \mathrm{C}$, com aumento de temperatura a taxa de $20^{\circ} \mathrm{C} \min ^{-1}$ até $60{ }^{\circ} \mathrm{C}$, então a temperatura foi elevada até $290{ }^{\circ} \mathrm{C}$ a $5^{\circ} \mathrm{C} \mathrm{min}^{-1}$, onde permaneceu por 5 minutos e, por fim, a temperatura foi elevada até $300{ }^{\circ} \mathrm{C}$ a taxa de $10{ }^{\circ} \mathrm{C} \mathrm{min}{ }^{-1}$, onde foi mantida constante durante 10 minutos. A quantificação foi feita pelo modo de padronização interna com base nas curvas de calibração.

A identificação dos HPA foi feita por comparação dos tempos de retenção com padrões de referência da Accustandard (EUA) e através da razão massa/carga (m/z). A identificação dos compostos alquilados (alquil-naftalenos, alquil-fluorenos, alquil-fenantrenos/antracenos, alquil-dibenzotiofenos e alquil-fluorantenos/pirenos) foi realizada através da razão $\mathrm{m} / \mathrm{z}$ e a quantificação baseada nos respectivos HPA não alquilados (Tabela $1 \mathrm{~S}$ ).

Os limites de detecção do método (LDM) foram definidos como 3 vezes o desvio padrão da quantificação de 7 replicatas de uma amostra (LDM = 7 x DP) ${ }^{36}$ o Limite de Quantificação do Método foi definido como 3 vezes o LDM (Tabela 2S). 


\section{Procedimentos para o controle de qualidade}

Para cada conjunto de amostras extraídas foi analisado também um branco analítico ( $10 \mathrm{~g}$ de sulfato de sódio). Os brancos analíticos foram analisados de forma idêntica às amostras de tecidos biológicos. Foram analisados também brancos fortificados nas mesmas concentrações utilizadas nas amostras de tecidos biológicos. Foram consideradas válidas as amostras e brancos nas quais a recuperação do padrão sub-rogado esteve entre 60 e 120\%. Devido à inexistência de material de referência certificado (MR) de HPA em tecidos de tetrápodes marinhos, foi analisado o MR de tecido de mexilhão (NIST, SRM 2974a, Organics in Freeze-Dried Mussel Tissue - Mytilus edulis) utilizando tanto o soxhlet quanto micro-ondas para a extração. Todas as amostras de tecido adiposo e hepático dos quatro animais foram analisadas também sem fortificação, de forma a viabilizar a análise da recuperação dos compostos adicionados.

\section{Avaliação estatística dos resultados}

A avaliação estatística visou a avaliação da influência de seis fatores: animal marinho, tecido do animal, nível de concentração, método de extração, variabilidade do tecido e local de retirada do tecido para determinação de HPA totais. A influência de cada um dos fatores de entrada na variável de resposta (concentração total de HPA) foi avaliada a partir da Análise de Variância (ANOVA) com uso da Análise Fatorial para verificar a hipótese nula (H0) entre as variáveis. Todos os testes foram realizados considerando o nível de significância de $\alpha=0.05$ e considerando o valor de probabilidade ( $\mathrm{p}$-value) de cada teste.

\section{RESULTADOS E DISCUSSÕES}

\section{Avaliação do método de extração nos diferentes tecidos biológicos}

São descritos a seguir de forma resumida os resultados das
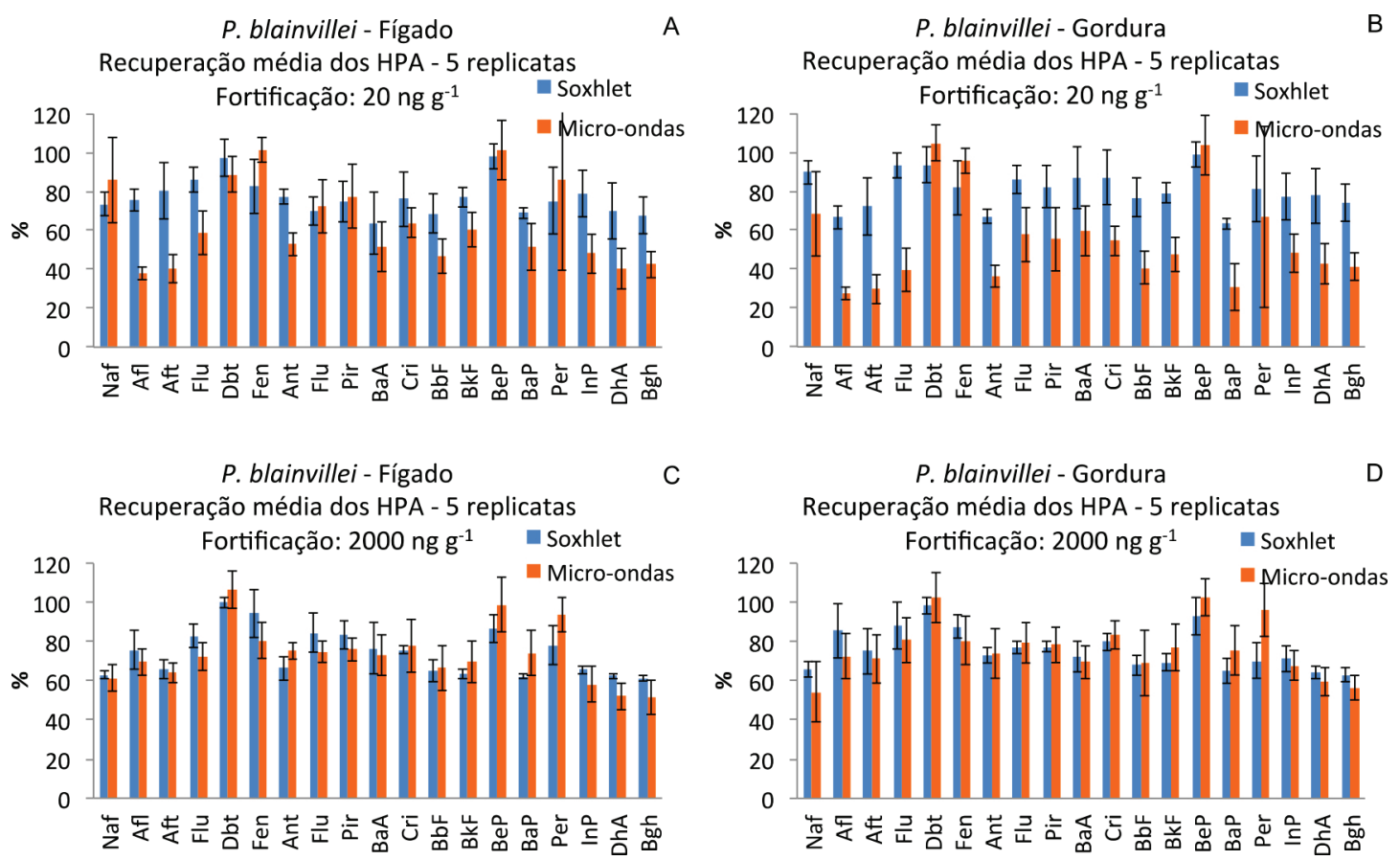

extrações em cada um dos tecidos analisados nos diferentes animais, pelos dois métodos de extração, soxhlet e micro-ondas, nos dois níveis de fortificação. A recuperação do padrão sub-rogado nas amostras variou entre 60 e $100 \%$. A análise do material de referência produziu resultados válidos pelos dois métodos de extração. Não foram detectados interferentes nos brancos analíticos. Na Tabela 1 é apresentada a síntese da recuperação dos HPA adicionados às amostras, nas 5 replicatas de cada tecido, nos diferentes níveis de fortificação para os diferentes métodos de extração empregados. Os resultados completos das análises são apresentados na Tabela $3 \mathrm{~S}$.

\section{Pontoporia blainvillei}

O teor de lipídios no tecido adiposo foi de $56 \%$, enquanto no tecido hepático o teor de lipídios foi de $7 \%$. As concentrações de todos os HPA nos tecidos de P. blainvillei sem a fortificação foram inferiores aos limites de detecção do método.

Na Figura 3 são apresentados os resultados médios de recuperação em percentagem de cada um dos HPA nas 5 replicatas de tecido hepático e de gordura nos dois níveis de fortificação e o desvio padrão das recuperações. De forma geral a recuperação dos HPA foi melhor quando a extração foi realizada por soxhlet do que quando foi realizada por micro-ondas em todos os casos. Além disso, o desvio padrão das recuperações dos HPA foi menor quando foi empregado o sistema soxhlet (Tabela 1).

\section{Chelonia mydas}

O teor de lipídios no tecido adiposo foi de $69 \%$, enquanto no tecido hepático o teor de lipídios foi de $8 \%$. Nas amostras de gordura da $C$. mydas, sem a fortificação, foram detectados naftaleno (19,6 ng g ${ }^{-1}$ extraído por soxhlet e $20,6 \mathrm{ng} \mathrm{g}^{-1}$ extraído por micro-ondas), fenantreno $\left(3,4 \mathrm{ng} \mathrm{g}^{-1}\right.$ por soxhlet e $5,4 \mathrm{ng} \mathrm{g}^{-1}$ por micro-ondas), pireno $\left(3,1 \mathrm{ng} \mathrm{g}^{-1}\right.$ por soxhlet e $3,5 \mathrm{ng} \mathrm{g}^{-1}$ por micro-ondas) e criseno (3,4 $\mathrm{ng} \mathrm{g}^{-1}$ por soxhlet e $3,4 \mathrm{ng} \mathrm{g}^{-1}$ por microondas). Para a avaliação das recuperações dos HPA adicionados, essas concentrações foram descontadas das concentrações das

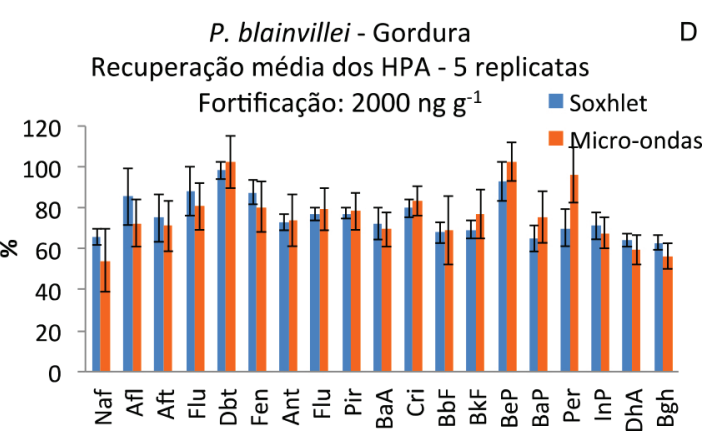
,

Figura 3. Recuperação percentual média dos HPA e desvio padrão das recuperações (barras verticais) nas 5 replicatas de tecido hepático (A e C) e gordura (B e D) de P. blainvillei fortificados com 20 (A e B) e $2000 \mathrm{ng}^{-1}$ (C, D) de HPA (peso úmido). Naf: Naftaleno, Afl: Acenaftileno, Aft: Acenafteno, Flu: Fluoreno, Dbt: Dibenzotiofeno, Fen: Fenantreno, Ant: Antraceno, Flu: Fluoreno, Pir: Pireno, BaA: Benzo[a]antraceno, Cri: Criseno, BbF: Benzo[b]fluoranteno, BkF: Benzo[k]fluoranteno, BeP: Benzo[e]pireno, BaP: Benzo[a]pireno, InP: Indeno[1,2,3,c-d]pireno, DhA: Dibenzo[a,h]antraceno, Bghi:Benzo[g,h,i]perileno 
amostras fortificadas. Nas amostras de fígado sem fortificação não foram detectados os HPA.

São apresentados na Figura 4 os resultados médios de recuperação em percentagem de cada um dos HPA nas 5 replicatas de tecido hepático e de gordura nos dois níveis de fortificação e o desvio padrão das recuperações. Assim como observado para os tecidos de P. blainvillei, a recuperação dos HPA em ambos os tecidos de $C$. mydas também foi superior quando o soxhlet foi empregado como método de extração e o desvio padrão das recuperações dos HPA foi menor (Tabela 1).

\section{Thalassarche melanophris}

O teor de lipídios no tecido adiposo foi de $50 \%$, enquanto no tecido hepático o teor de lipídios foi de $4 \%$. As concentrações de HPA nos tecidos avaliados de T. melanophris sem a fortificação foram inferiores aos limites de detecção do método.

Na Figura 5 são apresentados os resultados médios de recuperação em percentagem de cada um dos HPA nas 5 replicatas de tecido hepático e de gordura nos dois níveis de fortificação e o desvio padrão das recuperações. Assim como observado para os tecidos de P. blainvillei $e$ C. mydas, a recuperação dos HPA em tecido de T. melanophris foi maior quando a extração foi realizada por soxhlet do que quando foi realizada por micro-ondas e o soxhlet produziu um menor desvio padrão na recuperação dos HPA (Tabela 1).

\section{Balaenoptera brydei}

O teor de lipídios no tecido adiposo foi de $44 \%$, enquanto no tecido hepático foi de $8 \%$. As concentrações de HPA nos tecidos avaliados de B. brydei sem a fortificação foram inferiores aos limites de detecção do método.

Para o tecido de B. brydei (Figura 6), assim como para todas as outras espécies citadas anteriormente, a recuperação dos HPA foi melhor quando foi empregado o soxhlet como método de extração dos tecidos e este método produziu um menor desvio padrão na recuperação dos HPA (Tabela 1).

Apesar de ambos os métodos de extração empregados satisfazerem os critérios de qualidade analítica, os resultados das análises de
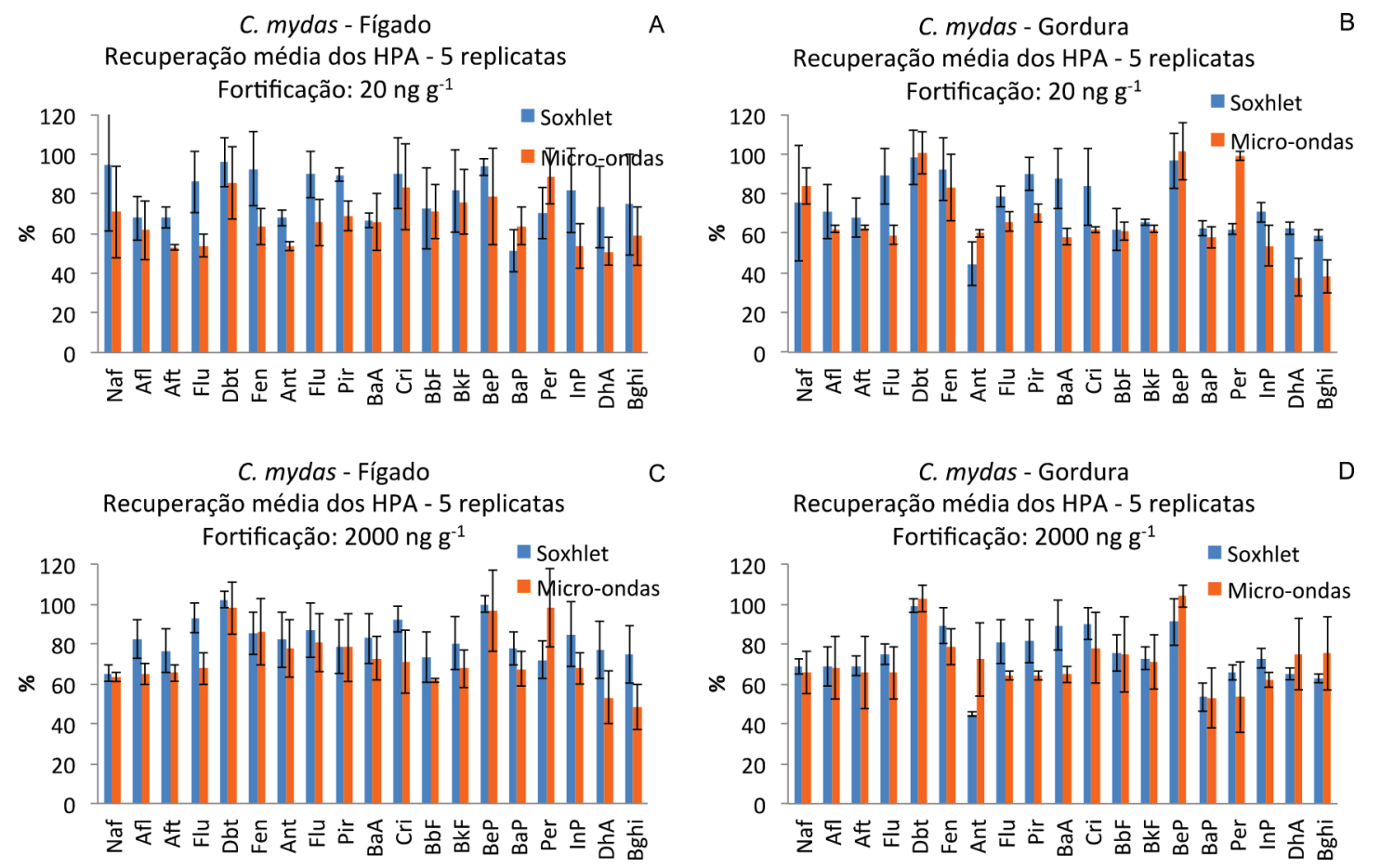

HPA em amostras de tecido adiposo e hepático dos quatro animais estudados mostraram que, independentemente do animal e do tipo de tecido, a extração por soxhlet foi mais exata, isto é apresentou maior recuperação dos compostos e, de forma geral, foi mais precisa, uma vez que produziu um menor desvio padrão na recuperação tanto para as amostras fortificadas com 20 quanto para as amostras fortificadas

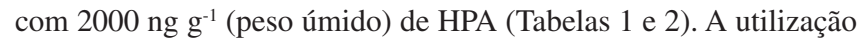
de micro-ondas para a extração dos HPA mostrou menor recuperação de HPA, especialmente para os HPA de 5 e 6 anéis aromáticos indeno[1,2,3-c,d]pireno, dibenzo[a,h]antraceno e benzo[ghi]perileno (Tabelas 1S e 2S, Material Suplementar).

A menor eficiência de extração no micro-ondas em relação ao soxhlet, para o método empregado, pode estar relacionada à constante dielétrica $(\varepsilon)$ baixa dos solventes utilizados, n-hexano $(\varepsilon=1,9)$ e do diclorometano $(\varepsilon=9,1)$ ou seja, esses solventes têm pouca capacidade de absorver micro-ondas. A USEPA ${ }^{14}$ sugere a utilização da mistura hexano-acetona para a extração de HPA em matrizes sólidas utilizando micro-ondas devido à maior capacidade de absorção de micro-ondas $(\varepsilon=20)$. A opção de não utilizar a acetona na extração por micro-ondas ocorreu em função de testes realizados previamente, onde foram encontrados interferentes no branco analítico mesmo sendo utilizada nesses testes a acetona de grau pesticida. Podemos considerar também o fato de que os tecidos biológicos e os lipídios sofrem cozimento com as micro-ondas e não há registro na literatura das consequências dessa degradação dos tecidos e lipídios para a análise de HPA em tetrápodes marinhos.

A análise estatística ANOVA comparando as técnicas de extração, os tecidos dos tetrápodes e os níveis de fortificação das amostras com HPA (Tabela 4S) mostrou, em alguns casos, diferenças significativas entre as técnicas de extração para os diferentes tecidos biológicos e para as diferentes concentrações de HPA. Apesar dessas diferenças significativas apontadas pelo teste estatístico, é necessário considerar que: 1) as concentrações originais de HPA nas amostras utilizadas foram inferiores ao limite de quantificação do método, exceto o tecido adiposo de $C$. mydas, onde os HPA detectados foram descontados da fortificação para a avaliação; 2) as amostras dos dois tecidos foram

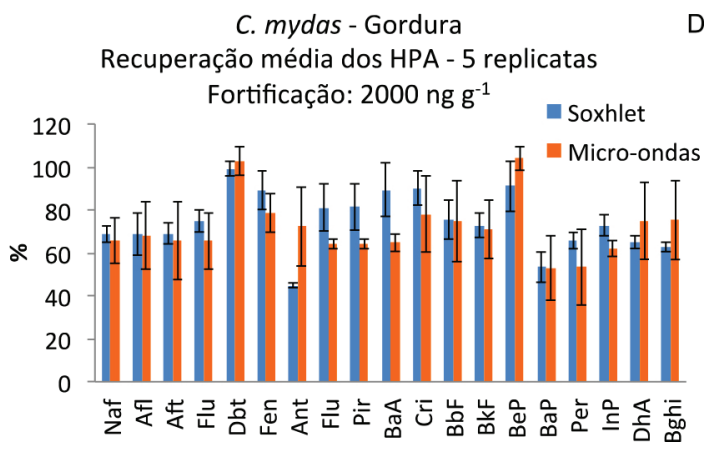

Figura 4. Recuperação percentual média dos HPA e desvio padrão das recuperações (barras verticais) nas 5 replicatas de tecido hepático (A e C) e gordura (B e D) de C. mydas fortificados com 20 (A e B) e $2000 \mathrm{ng} \mathrm{g}^{-1}$ (C, D) de HPA (peso úmido) 


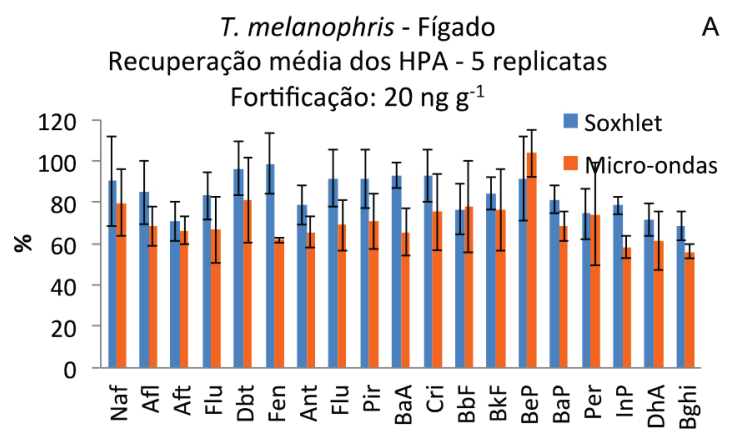

T. melanophris - Fígado

Recuperação média dos HPA - 5 replicatas

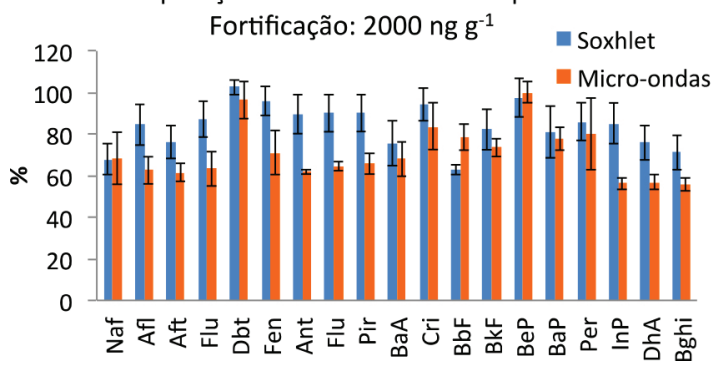

T. melanophris - Gordura

B

Recuperação média dos HPA - 5 replicatas Fortificação: $20 \mathrm{ng} \mathrm{g}^{-1}$

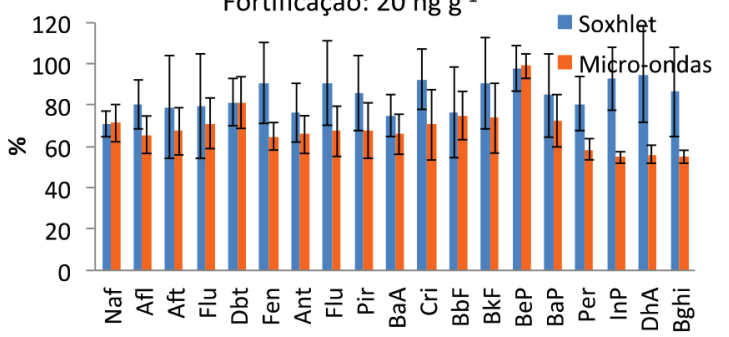

T. melanophris - Gordura

D

Recuperação média dos HPA - 5 replicatas

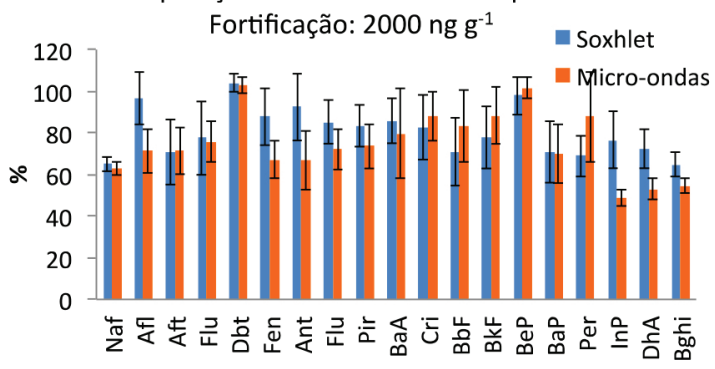

Figura 5. Recuperação percentual média dos HPA e desvio padrão das recuperações (barras verticais) nas 5 replicatas de tecido hepático (A e C) e gordura (B e D) de T. melanophris fortificados com 20 (A e B) e $2000 \mathrm{ng}^{-1}$ (C, D) de HPA (peso úmido)
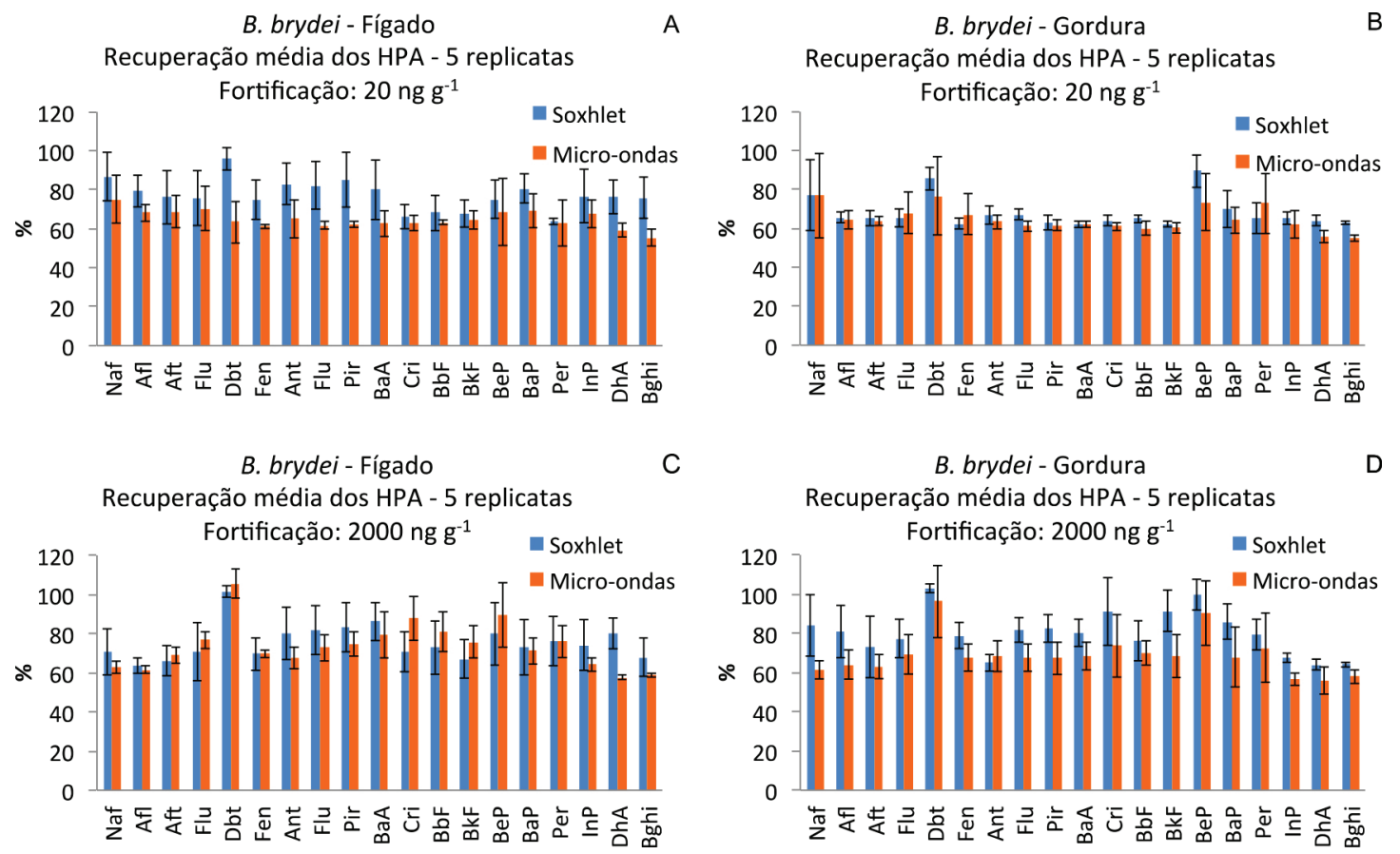

Figura 6. Recuperação percentual média dos HPA e desvio padrão das recuperações (barras verticais) nas 5 replicatas de tecido hepático (A e C) e gordura (B e D) de B. brydei fortificados com 20 (A e B) e $2000 \mathrm{ng}^{-1}$ (C, D) de HPA (peso úmido)

fortificadas com os HPA nas mesmas concentrações, portanto as concentrações nominais de HPA em ambos os tecidos são idênticas; 3 ) os critérios de qualidade analítico estabelecidos foram atendidos, portanto ambos os métodos de extração foram validados. Dessa forma a análise estatística reflete principalmente as variações das recuperações dos compostos entre os métodos de extração e entre os tecidos, e não invalida um ou outro método visto que ambos os métodos de extração, para ambos os tecidos, atenderam os critérios de qualidade do método analítico.
Avaliação da heterogeneidade dos tecidos e do local de retirada do tecido adiposo

As 45 amostras de tecidos de animais marinhos (P. blainvillei, C. mydas e S. magellanicus) obtidas para a avaliação da heterogeneidade dos tecidos e do local de retirada do tecido adiposo foram extraídas apenas por soxhlet em função dos resultados apresentados na avaliação do método de extração.

A recuperação do padrão sub-rogado em todas as replicatas, 
Tabela 1. Resumo das médias e desvio padrão de recuperação dos HPA adicionados aos tecidos para cada método de extração, soxhlet e micro-ondas, para cada tecido (gordura e fígado) e para cada nível de fortificação, 20 e $2000 \mathrm{ng} \mathrm{g}^{-1}$ peso úmido

\begin{tabular}{|c|c|c|c|c|}
\hline \multirow{2}{*}{ Tecido } & \multicolumn{2}{|c|}{ Fortificação: $20 \mathrm{ng} \mathrm{g}^{-1}$} & \multicolumn{2}{|c|}{ Fortificação: $2000 \mathrm{ng} \mathrm{g}^{-1}$} \\
\hline & Gordura & Fígado & Gordura & Fígado \\
\hline Recuperação dos HPA & Média (\%) & Média (\%) & Média (\%) & Média (\%) \\
\hline P. blainvillei (soxhlet) & $81 \pm 13$ & $77 \pm 13$ & $76 \pm 11$ & $74 \pm 13$ \\
\hline P. blainvillei (micro-ondas) & $55 \pm 26$ & $64 \pm 24$ & $76 \pm 17$ & $73 \pm 16$ \\
\hline C. mydas (soxhlet) & $75 \pm 18$ & $79 \pm 19$ & $75 \pm 15$ & $83 \pm 13$ \\
\hline C. mydas (micro-ondas) & $67 \pm 19$ & $67 \pm 17$ & $72 \pm 17$ & $73 \pm 17$ \\
\hline T. melanophris (soxhlet) & $85 \pm 17$ & $84 \pm 14$ & $81 \pm 15$ & $84 \pm 12$ \\
\hline T. melanophris (micro-ondas) & $69 \pm 13$ & $71 \pm 16$ & $75 \pm 18$ & $71 \pm 14$ \\
\hline B. brydei (soxhlet) & $68 \pm 9$ & $77 \pm 12$ & $80 \pm 13$ & $76 \pm 13$ \\
\hline B. brydei (micro-ondas) & $65 \pm 10$ & $65 \pm 9$ & $69 \pm 13$ & $74 \pm 14$ \\
\hline
\end{tabular}

tanto de tecido adiposo quanto de tecido hepático variou entre $61 \%$ e $93 \%$. Todas as amostras de tecidos adiposo e hepático retiradas das diferentes partes dos animais assim como as amostras compostas desses tecidos apresentaram concentrações de HPA inferiores aos limites de detecção do método analítico. Este fato impediu a avaliação sobre alguma preferência na bioacumulação de HPA em uma ou outra parte no tecido destes animais.. A ausência de HPA na maioria dos tecidos analisados também não permitiu verificar a diferença de bioacumulação entre o tecido hepático e adiposo.

\section{CONCLUSÕES}

Os resultados obtidos pelos dois métodos de extração, para os dois tecidos, para os quatro animais produziram recuperações aceitáveis tanto do composto sub-rogado como dos HPA adicionados às amostras. Apesar do teste estatístico mostrar, em alguns casos, diferenças significativas entre os métodos de extração e entre os tecidos, os dois métodos de extração atenderam aos critérios de qualidade dos resultados analíticos. A extração por soxhlet produziu uma melhor recuperação dos HPA e um menor desvio padrão da recuperação entre as replicatas do que a extração por micro-ondas.

Devido ao grande número de amostras analisadas, a extração pelo soxhlet ocorreu de forma mais rápida do que pelo micro-ondas em função da utilização de 23 sistemas de soxhlet, que permitiram um maior número de extrações simultâneas.

A avaliação da heterogeneidade dos tecidos e do local de retirada do tecido adiposo ficou comprometida, pois não foram detectados HPA em nenhuma das amostras de nenhum dos tecidos analisados.

Para a continuidade deste estudo sugere-se aos futuros trabalhos que envolvam a avaliação da bioacumulação de HPA por tetrápodes marinhos que sejam coletados, sempre que possível, o tecido do fígado e a gordura em diferentes partes do animal e que a análise do conjunto total de amostras seja realizada quando uma dessas amostras apresentar concentrações de HPA maiores que o limite de detecção.

\section{MATERIAL SUPLEMENTAR}

No Material Suplementar são informados os íons de quantificação e de confirmação para a análise dos HPA (Tabela 1S), os limites de detecção e de quantificação do método analítico (Tabela 2S), o conjunto completo de concentrações e de recuperações dos HPA adicionados em todas as amostras de tecidos biológicos analisadas (Tabela 3S) e os resultados do teste estatístico (Tabela 4S). Esse material está disponível em http://quimicanova.sbq.org.br, na forma de arquivo PDF, com acesso livre.

\section{AGRADECIMENTOS}

Esse trabalho foi financiado pelo Petróleo Brasileiro S.A (Petrobras) e faz parte das atividades da otimização de metodologia analítica no âmbito do PMP-BS (Projeto de Monitoramento de Praias da Bacia de Santos) realizado em atendimento às exigências do processo de licenciamento ambiental da Atividade de Produção e Escoamento de Petróleo e Gás Natural do Polo Pré-Sal da Bacia de Santos - ETAPA 2 conduzido pelo IBAMA. Os autores agradecem ao Projeto Biopesca pela disponibilização de algumas das amostras de tecido utilizadas nesse trabalho. Os autores agradecem também ao Centro de Pesquisas \& Desenvolvimento Leopoldo Américo Miguez de Mello (CENPES) da PETROBRAS e aos revisores anônimos da revista Química Nova pelas discussões e valiosas sugestões para a melhoria do trabalho.

\section{REFERÊNCIAS}

1. Golomb, D.; Barry, E.; Fisher, G.; Varanusupakul, P.; Koleda, M.; Rooney, T.; Atmos. Environ. 2001, 35, 6245.

2. Kowalewska, G.; Konat, J.; Oceanologia 1997, 39, 83.

3. Zhang, S.; Zhang, Q.; Darisaw, S.; Ehie, O.; Wang, G.; Chemosphere 2007, 66, 1057

4. Yu, Y.; Xu, J.; Wang. P.; Sun, H.; Dai, S.; J. Hazard. Mater. 2009, 165, 494.

5. Baumard, P.; Budzinski, H.; Garrigues, P.; Narbonne, J. F.; Burgeot, T.; Michel, X.; Belloccq, J.; Mar. Environ. Res. 1999, 47, 415.

6. Lourenço, R. A.; Oliveira, F. F.; Souza, J. M.; Nudi, A. H.; Wagener, A. L. R.; Meniconi, M. F. G.; Francioni, E.; Environ. Sci. Pollut. Res. 2016, 23,17113 .

7. Webster, L.; Tronczynski, J.; Korytar, P.; Booij, K.; Law, R.; ICES Tech. Mar. Environ. Sci. 2009, 45, 26.

8. Wan, Y.; Jin, X.; Hu, J.; Jin, F.; Environ. Sci. Technol. 2007, 41, 3109.

9. Nakata, H.; Sakai, Y.; Miyawaki, T.; Takemura, A.; Environ. Sci. Technol. 2003, 37, 3513

10. Broman, D.; Näuf, C.; Lundbergh, I.; Zebühr, Y.; Environ. Toxicol. Chem. 1990, 9, 429.

11. Takeuchi, I.; Miyoshi, N.; Mizukawa, K.; Takada, H.; Ikemoto, T.; Omori, K.; Tsuchiya, K.; Mar. Pollut. Bull. 2009, 58, 663.

12. Oluseyi, T.; Olayinka, K.; Alo, B.; Smith, R. M.; Afr. J. Environ. Sci. Technol. 2011, 5, 482.

13. https://www.epa.gov/sites/production/files/2015-12/documents/3540c. pdf, acessada em dezembro de 2018.

14. https://www.epa.gov/sites/production/files/2015-12/documents/3546. pdf, acessada em dezembro de 2018. 
15. https://www.epa.gov/sites/production/files/2015-06/documents/epa3545a.pdf, acessada em dezembro de 2018.

16. https://www.epa.gov/sites/production/files/2015-12/documents/3550c. pdf, acessada em dezembro de 2018.

17. Giergielewicz-Mozajska, H.; Dabrowski, L.; Namiésnik, J.; Crit. Rev. Anal. Chem. 2001, 31, 149.

18. Méndez-Fernandez, P.; Taniguchi, S.; Santos, M. C. O.; Cascão, I.; Quérouil, S.; Martín, V. Tejedor, M.; Carrillo, M.; Rinaldi, C.; Rinaldi, R.; Montone, R. C.; Environ. Pollut. 2018, 236, 785.

19. Méndez-Fernandez, P.; Polesi, G.; Taniguchi, S.; Santos, M. C. O.; Montone, R. C.; Mar. Pollut. Bull. 2016, 107, 364.

20. Montone, R. C.; Taniguchi, S.; Colabuono, F. I.; Martins, C. C.; Cipro, C. V. Z.; Barroso, H. S.; da Silva, J.; Bícego, M. C.; Weber, R. R.; Mar. Pollut. Bull. 2016, 106, 377.

21. Cipro, C. V. Z.; Colabuono, F. I.; Taniguchi, S.; Montone, R. C.; Mar. Pollut. Bull. 2013, 77, 396.

22. Colabuono, F. I.; Barquete, V.; Taniguchi, S.; Ryan, P. G.; Montone, R. C.; Mar. Pollut. Bull. 2014, 83, 241

23. Dias, P. S.; Cipro, C. V. Z.; Taniguchi, S.; Montone, R. C.; Mar. Pollut. Bull. 2013, 74, 435 .

24. Leonel, J.; Taniguchi, S.; Sasaki, D. K.; Cascaes, M. J.; Dias, P. S; Botta, S.; Santos, M. C. O.; Montone, R. C.; Chemosphere 2012, 86, 741.

25. Geraci, J. R.; Lounsbury, V. J.; Marine Mammals Ashore: a field guide for strandings, $1^{\text {st }}$ ed., Texas A\&M Sea Grant Publications: Texas, 1993.
26. Pugliares, K. R.; Bogomolni, A.; Touhey, K. M.; Herzig, S. M.; Harry, C. T.; Moore, M. J.; Marine Mammal Necropsy: An introductory guide for stranding responders and field biologists, $1^{\text {st }}$ ed., Woods Hole Oceanographic Institution: Massachusetts, 2007.

27. https://www.epa.gov/sites/production/files/2015-07/documents/epa8270d.pdf, acessada em dezembro de 2018.

28. Jayaraman, S.; Pruell, R. J.; McKinney, R.; Chemosphere 2001, 44, 181.

29. Tapie, N.; Budzinski, H.; Le Ménach, K.; Anal. Bioanal. Chem. 2008, 391,2169

30. https://www.epa.gov/sites/production/files/2015-10/documents/ method_1699_2007.pdf, acessada em dezembro de 2018.

31. Sericano, J. L.; Tese de Doutorado, College of Geosciences and Maritime Studies of Texas A\&M University, Estados Unidos da América, 1993.

32. Taniguchi, S.; Montone, R. C.; Bícego, M. C.; Colabuono, F. I.; Weber, R. R.; Sericano, J. L.; Mar. Pollut. Bull. 2009, 58, 129.

33. https://www.epa.gov/sites/production/files/2015-12/documents/3610b. pdf, acessada em dezembro de 2018.

34. https://www.epa.gov/sites/production/files/2015-12/documents/3630c. pdf, acessada em dezembro de 2018.

35. https://www.epa.gov/sites/production/files/2015-12/documents/3640a. pdf, acessada em dezembro de 2018.

36. Wade, T. L.; Cantillo, Y. A.; Use of Standards and Reference Materials in the Measurement of Chlorinated Hydrocarbon Residues, $1^{\text {st }}$ ed., Paris, 1996. 